\title{
Lung cancer in women
}

\author{
DAVID J.B. ASHLEY AND H. DUNCAN DAVIES
}

From Morriston Hospital, Swansea

\begin{abstract}
Eighty-three instances of lung cancer in women are presented. The frequency of the condition is lower in women than in men but the tumours in women tend to be less well differentiated and are less likely to be resectable than in men. The frequency of extrathoracic metastases at the time of diagnosis is greater in women than in men. It is suggested that the immunological defences of women are better than those of men because of sex-linked genes, present in double dose in the female, which are concerned with the immunological mechanisms, and that the clinically apparent tumours are those which, by virtue of their greater intrinsic malignancy, can overcome the defence mechanisms.
\end{abstract}

Malignant disease of the lower respiratory tract is substantially less common in women than in men. This difference in incidence in England and Wales increased between 1913 and 1943 but has remained more or less constant since then (Myddelton, 1965). The differing frequencies of the tumour in the two sexes are usually related to the lower frequency of squamous-celled carcinoma in women which in turn is attributed to the higher prevalence of cigarette smoking among men and the greater likelihood that men would work in an atmosphere of high air pollution.

The present contribution is a study of the clinical, histological, and biological features of lung cancer in 83 instances of this tumour diagnosed in women by clinical, radiological, and histological examination at Morriston Hospital, Swansea, during the past 15 years and a comparison of these features in 1,353 lung cancers in men (Ashley and Davies, 1967).

\section{FREQUENCY}

The ratio between men and women in this series was $16: 1$; if only histologically proven cases are included the ratio is $12: 1$. The proportion of women is lower than in most of the other reported series (Table I), and is lower than that for England and Wales as a whole. The total number of deaths in women recorded by the Registrar General as due to lung cancer in the six years 1958 to 1963 was 12,786 ; the total for the same six years in men was 78,235 , a male to female ratio of $6 \cdot 1: 1$. The age distribution of the female population differs markedly from that of the male and, if the age specific death rates for this tumour in men had

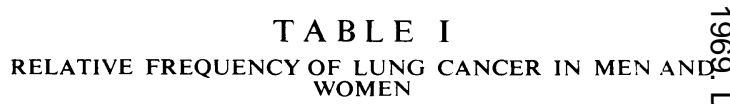

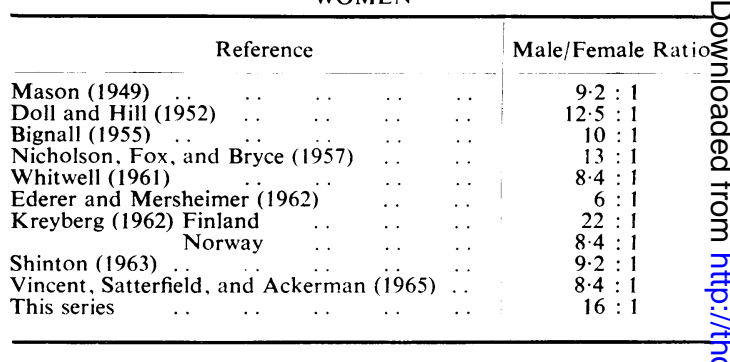

applied to the female population, the number of deaths expected wou'd have bien 105,437, ratio of $8 \cdot 1: 1$.

The relatively lower frequency of lung cancer in women in this series may be related to the culturap habits of the peop!e of this part of Wales, possiblyo to a lower prevalence of cigarette smoking among the women of Wales. This view is supported bo the finding of a Standardized Mortality Ratio for. lung cancer of 81 in men and 58 in women for theos Welsh Hospital Region, which is coterminoun with the Principality of Wales (Registrar GeneralN 1965). In 1963 there were 19,746 deaths from lung cancer among men in England and 3,558 suck deaths among women, a male to female ratio of $5.55: 1$, whereas in Wales there were 1,011 deaths in men and 119 in women, a male to female ratio of $8.4: 1$ (Registrar General, 1965). This differences is highly significant.

\section{HISTOLOGICAL TYPES OF LESION}

Material was available from either bronchiaf biopsy or open operation in 56 cases. The histoo 
logical classification used was that of Ashley and Davies (1967) in which five types of lung cancer were recognized-well and poorly differentiated squamous carcinoma, well and poorly differentiated adenocarcinoma, and undifferentiated carcinoma. Examples of the carcinoid (argentaffin) tumour of the bronchus were excluded as it was considered that these form an intrinsically different tumour type.

The data are presented in Table II, in which they are subdivided by the type of differentiation,

\section{T A B L E II}

HISTOLOGICAL TYPES OF LUNG CANCER

\begin{tabular}{|c|c|c|c|c|c|}
\hline \multicolumn{3}{|c|}{ Type of Differentiation } & \multicolumn{2}{|c|}{$\begin{array}{l}\text { Females } \% \\
\text { No. }\end{array}$} & \multirow{2}{*}{$\begin{array}{c}\begin{array}{c}\text { Males } \\
\%\end{array} \\
60 \\
11 \\
29\end{array}$} \\
\hline $\begin{array}{l}\text { Squamous } \\
\text { Glandular } \\
\text { Undifferentiated }\end{array}$ & $\begin{array}{l}\cdots \\
\cdots\end{array}$ & $\begin{array}{l}\cdots \\
\cdots\end{array}$ & $\begin{array}{l}13 \\
16 \\
27\end{array}$ & $\begin{array}{l}23 \\
28 \\
48\end{array}$ & \\
\hline \multicolumn{3}{|c|}{$\begin{array}{l}\text { Degree of differentiation } \\
\text { Well differentiated } \\
\text { Poorly differentiated } \\
\text { Undifferentiated }\end{array}$} & $\begin{array}{r}7 \\
19 \\
30\end{array}$ & $\begin{array}{l}12 \cdot 5 \\
34 \\
53 \cdot 5\end{array}$ & $\begin{array}{l}18 \cdot 5 \\
45 \cdot 5 \\
35\end{array}$ \\
\hline
\end{tabular}

whether glandular, squamous, or undifferentiated, and secondly by the degree of differentiation of the least well differentiated part of the tumour. The proportions of the different types in women are compared with those derived from a previously reported survey of 666 cases of lung cancer in men (Ashley and Davies, 1967). The rare lesion, adenosquamous carcinoma, in which both glandular and squamous differentiation are seen in the same tumour, was not represented in this series.

There was a significantly lower proportion of tumours of squamous type in the women and a significant excess of glandular and of undifferentiated carcinomata. The proportion of cases in which the least well differentiated part of the tur.our was classified as undifferentiated was also significantly higher in the women.

Similar observations to these have been made in many reported series (Mason, 1949; Shinton, 1963 ; Hanbury, 1964 ; Vincent, Satterfield, and Ackerman, 1965). The deficit of cases of squamous-celled carcinoma may be attributed to the lower frequency of chronic irritation in the female bronchi, whether the result of cigarette smoking or of chronic bronchial inflammation. The lower degree of differentiation in tumours in women was a feature which was noted by Nicholson, Fox, and Bryce (1957), Whitwell (1961), Kreyberg (1962), and Shinton (1963) although Vincent et al. (1965) found the proportion of undifferentiated tumours to be equal in the two sexes.

\section{AGE INCIDENCE}

The age incidence in this series is given in Table III. The mean age at diagnosis was 56.1 years, whereas in men the mean age at diagnosis in those presenting with the symptom cough was 58.3 years, and in men in whom the tumour was diagnosed as a result of routine radiography the mean

T A B L E I I I

AGE INCIDENCE

\begin{tabular}{c|r}
\hline Age Group & No. \\
\hline$<40$ years & 4 \\
$41-50$ & 16 \\
$51-60$ & 34 \\
$61-70$ & 25 \\
$>70$ & 4
\end{tabular}

age was 60.7 years. The age at diagnosis has been noted to be lower in women than in men in a number of other series (Mason, 1949 ; Nicholson et al., 1957 ; Whitwell, 1961). This is a particularly surprising finding because the female population is relatively greater in the older age groups than the male and, in a lesion which shows an increasing incidence with increasing age, as does lung cancer, a relatively higher average age would be expected in women than in men.

The histological features of lung cancer in women include a greater proportion of illdifferentiated carcinomata than in men, and as these lesions tend to occur in men at an earlier age than those of more differentiated type (Ashley and Davies, 1967) it is possible that the age difference may be due to some factor such as this. Another possibility is that the habit of cigarette smoking is commoner in the younger women than in the older and therefore that the frequency of lung cancer may be relatively higher in younger women than in older women.

\section{SYMPTOMS}

The four major symptoms attributable to lung cancer are cough, dyspnoea, chest pain, and haemoptysis. The distribution of symptoms in the patients in this series is set out in Table IV and

T A B L E I V

SYMPTOMS AT THE TIME OF DIAGNOSIS

\begin{tabular}{|c|c|c|c|c|c|}
\hline & & & No. & $\%$ & $\underset{\%}{\text { Males }}$ \\
\hline $\begin{array}{ll}\text { Cough .. } & \ldots \\
\text { Dyspnoea } & \ldots \\
\text { Chest pain } & \ldots \\
\text { Haemoptysis } & \ldots \\
\text { Routine radiograph } \\
\text { Secondaries } \quad \ldots\end{array}$ & $\begin{array}{l}\cdots \\
\cdots \\
\cdots \\
\cdots \\
\cdots\end{array}$ & $\begin{array}{l}\cdots \\
\cdots \\
\cdots \\
\cdots \\
\cdots\end{array}$ & $\begin{array}{r}56 \\
26 \\
37 \\
25 \\
6 \\
25\end{array}$ & $\begin{array}{l}67 \cdot 5 \\
31 \\
45 \\
30 \\
7 \\
30\end{array}$ & $\begin{array}{l}61 \\
47 \\
46 \\
39 \\
5 \cdot 1 \\
11 \cdot 4\end{array}$ \\
\hline
\end{tabular}


is compared with the data from 1,353 men suffering from this disease. The proportions of women complaining of cough and chest pain did not differ significantly from the proportions of men complaining of these symptoms. Dyspnoea and haemoptysis were less common in women than in men. Shortness of breath in patients with lung cancer is often the result of a relatively small decrease in respiratory capacity in an individual who already suffers from respiratory impairment, often as a consequence of chronic bronchitis and emphysema. Chronic lung infection of this type is less common in women than in men and it is probable that the lower prevalence of dyspnoea in these patients is related to their general respiratory health rather than to specific biological differences in the tumours. Haemoptysis, on the other hand, is more often associated with tumours showing squamous differentiation than those of glandular or undifferentiated pattern (Ashley and Davies, 1967), and the low proportion of women complaining of this symptom may be related to the lower frequency with which lung cancer is squamous in women.

The proportion of patients in whom the tumour came to light as the result of routine radiography was small in both men and women and did not differ significantly in the two sexes.

There was a significant excess of women in whom extrathoracic metastases were detectable at the time of diagnosis. Six of these had bony secondary deposits at the time of diagnosis. Among the 56 patients in whom histological confirmation of the diagnosis was available, 18 had extrathoracic secondary deposits at the time of diagnosis. The numbers of men with secondary deposits in each of the histological types was recorded in the previous paper (Ashley and Davies, 1967): when these rates were applied to the women in each of the histological types a total of seven with metastases would have been expected.

\section{BRONCHOSCOPIC APPEARANCES}

Bronchoscopy was carried out in 78 of the patients in this series (Table V) and tumour was found in $51(65 \%)$. In a comparable series of men bronchoscopic evidence of pulmonary neoplasm was obtained in $55 \%$. This difference was not statistically significant.

\section{OPERABILITY}

Surgical excision of the tumour offers the only present hope of cure in cases of lung cancer. Eleven of the patients in this series had lesions
T A B L E V

BRONCHOSCOPIC APPEARANCES AND OPERABILITY

\begin{tabular}{|c|c|c|c|c|c|}
\hline & & \multicolumn{3}{|c|}{ B ronchoscopy } & \multirow[b]{2}{*}{ Total } \\
\hline & & Positive & Negative & Not done & \\
\hline $\begin{array}{l}\text { Not resectable } \\
\text { Resectable }\end{array}$ & $\begin{array}{l}. \\
\therefore\end{array}$ & $\begin{array}{r}48 \\
3\end{array}$ & $\begin{array}{r}19 \\
8\end{array}$ & $\underline{5}$ & $\begin{array}{l}72 \\
11\end{array}$ \\
\hline Total ... & . & 51 & 27 & 5 & 83 \\
\hline
\end{tabular}

which were resected $(13.4 \%)$. This is a lower proportion than in the series of men $(21 \%)$. The difference approaches statistical significance. Two $₫$ patients refused thoracotomy, and in a further: seven the lesion was found at thoracotomy to be inoperable.

The proportion of resectable cases in both the ${ }^{\text {? }}$ men and women is lower than reported by others. $\vec{c}$ It is suggested that this is because almost alle patients suspected of having bronchial tumoursare sent for investigation to the joint medical ando surgical chest units at Morriston Hospital, and selection of potentially operable cases at othero hospitals is at a minimum. A lower resectability rate in women was also noted by Nicholson andō his colleagues (Nicholson et al., 1957) and theyo attributed this to the higher frequency of illo differentiated tumours in their female patients. In $\overrightarrow{\vec{B}}$ the present series data on the operability of the 3 different histological types of tumour were available from the men (Ashley and Davies, 1967) When the male percentages were applied to the numbers of the different types of tumour in the female series a total of 18 cases might have beenx expected to have resectable lesions, whereas onlyo 11 did so. This difference in the proportion of patients with resectable lesions in the groups of men and women with histologically classifiable tumours was statistically significant.

In the men it was noted that the site of ther lesion, whether accessible to the bronchoscope or not, had an effect on the feasibility of surgican excision (Ashley and Davies, 1967). The expected frequency of operable tumours if the resection rates for men in the two groups, bronchoscopyw positive and bronchoscopy negative, had applied? were calculated. Eleven cases in this series were operable; 16.4 would have been expected. The lower operability rate is therefore not the con? sequence of a higher frequency of more proximato tumours.

The presence of extrathoracic metastases is $a \stackrel{\mathbb{Q}}{\mathbb{Q}}$ bar to thoracic surgical treatment. The higher pro $\frac{\mathbb{2}}{2}$ portion of women who had such metastases at the time of diagnosis also influences the proportion of women with operable lesions. 


\section{SMOKING HISTORY}

A history relevant to cigarette smoking was available in 56 cases; 23 of these women $(41 \%)$ were non-smokers. The mean age of the smokers $(55$ years) was slightly lower than that of the nonsmokers (57.2 years). The proportion of nonsmokers in this series agrees well with the $40 \%$ recorded by Doll and Hill (1952) and the 36\% recorded by Hanbury (1964) and is greatly in excess of the proportion of non-smokers in men $(2 \cdot 8 \%)$. No significant differences were observed in the distribution of histological types of tumour among the smokers and non-smokers (Table VI). This observation agrees with the finding in the

\section{T A B L E V I}

SMOKING HISTORY

(a) Type of Tumour

\begin{tabular}{l|c|c|c|c}
\hline & Squamous & Glandular & $\begin{array}{c}\text { Undifferen- } \\
\text { tiated }\end{array}$ & Total \\
\hline $\begin{array}{c}\text { Non-smokers } \\
\begin{array}{c}\text { Cigarette } \\
\text { smokers }\end{array}\end{array}$ & 2 & 6 & 6 & 23 \\
\hline
\end{tabular}

(b) Amount of Tobacco Consumed

\begin{tabular}{c|r} 
Cigarettes $<5 /$ day & 7 \\
$6-15$ & 11 \\
$16-25$ & 9 \\
225 & 4 \\
'Heavy' & 2
\end{tabular}

men of this series but disagrees with the observations of Kreyberg (1962) in men and of Vincent et al. (1965) in women (Ashley and Davies, 1967). It is our view that cigarette smoking is an active contributory factor in the oncogenesis of pulmonary neoplasm but that the type of differentiation is dependent on the presence or absence of squamous metaplasia in the bronchial tree and that this in turn is related to smoking and also to chronic infection and to atmospheric pollution.

\section{FOLLOW-UP DATA}

The conventional assessment of treatment of malignant disease by study of the five-year survival rate is not applicable to a tumour of such poor prognosis as lung cancer. In this series followup from the date of diagnosis was available in 73 instances. Those patients who died within one month of thoracotomy, whether the tumour was resectable or not, have been excluded from the analysis because of the possibility that the stress of operation may have hastened death in these cases (Table VII). The number of patients with
T A B L E V I I

FOLLOW-UP DATA

\begin{tabular}{l|ccc|c}
\hline & At 6 months & At 12 months & At 24 months & Total \\
\cline { 2 - 5 } $\begin{array}{l}\text { Not resected } \\
\text { Resected }\end{array}$ & $26(41 \%)$ & $14(22 \%)$ & $4(6 \cdot 3 \%)$ & 63 \\
\hline Total & 36 & 21 & 6 & 10 \\
\hline $\begin{array}{l}\text { Males } \\
\text { (not resected) }\end{array}$ & $35 \%$ & $13.5 \%$ & $5 \cdot 1 \%$ & 73 \\
\hline
\end{tabular}

resectable lesions is too small for assessment. Twenty per cent of these women were alive two years after lung resection; in the men $40 \%$ were still alive at two years: this difference does not approach statistical significance. In the inoperable cases there was a slightly higher proportion of women alive at each of the three survival periods studied, but by two years the difference was small.

A poorer general prognosis in women than in men was noted in the Manchester series (Nicholson et al., 1957) but a better survival at five years was noted in operable lung cancers in women by Bignall and Moon (1955) and by Ederer and Mersheimer (1962). Nicholson and his colleagues (1957) attributed the poorer prognosis to the higher proportion of poorly differentiated tumours among women, as these tumours have often been shown to be intrinsically more malignant (Whitwell, 1961 ; Shinton, 1963 ; Ashley and Davies, 1967). The data presented above, however, suggest that lung cancer in women is less likely to be operable than in men when allowance is made for the histological type of neoplasm.

\section{DISCUSSION}

Consideration of the data presented above from our series of cases and from the reported series of lung cancer in women allows a concept of the character of this disease in women to be formed. Lung cancer is less common in women than in men, it is less likely to be of the squamous-cell type, and more likely to be of the glandular type or to be undifferentiated. The degree of differentiation is less than in men. The tumour is likely to occur at a somewhat earlier age and is more likely to present symptoms at a time when extrathoracic metastases are already present. The tumour is as likely to be accessible to the endoscopist as in men and is less likely to be accessible to surgical excision. The prognosis of lung cancer in women is worse than in men.

This is a curious situation. In women lung cancer is less common, but when it occurs is less likely to be resectable. It has been shown that the 
difference in resectability cannot be explained on the basis of the histological type of tumour or on the anatomical localization in the bronchial tree. The significantly higher proportion of patients in whom extrathoracic metastases were present at the time of diagnosis affects the overall prognosis but cannot be explained on the basis of the histological type of lesion. An alternative hypothesis is put forward.

One at least of the genes concerned in the immunological defence mechanism of the body is carried in the X chromosome (McKusick, 1962) ; mutation at this locus leads to the clinical condition of agammaglobulinaemia in which there is a deficiency of a circulating immunoglobulin and also a deficiency of plasma-cell reaction to foreign antigens. By virtue of their double complement of $\mathrm{X}$ chromosome women have a lower frequency of agammaglobulinaemia and, by inference, a better immunological capacity. It is suggested that those tumours of the lung which become clinically apparent are the ones in which the multiplying neoplastic cells are able to overcome the immunological defences of the body which would otherwise treat them as foreign cells and destroy them by a similar reaction to that seen after tissue transplantation. In women, with a better defence mechanism, fewer tumours would overcome the defences but those which did would be intrinsically more malignant and less amenable to therapy.

This hypothesis would account for the lower proportion of lung cancers in women, which cannot be completely explained by the lower proportion of women who are cigarette smokers. It would account for the reduced frequency with which the tumours when they occur are resectable, for the higher proportion of neoplasms of histologically undifferentiated type, and for the generally poorer prognosis in lung cancer in women. The reported better survival after lung resection in women (Bignall and Moon, 1955; Ederer and Mersheimer, 1962) is explicable if in these cases a balance between the immune de- fences and the advancing tumour is held rathe more securely in the case of the less 'malignand tumours in women than in men.

A similar explanation has been invoked (Ashley? 1967) to explain the differences in the natural hise tory of lung cancer in miners and in non-miners It was then suggested that the immunologicat defences of the lung which had been invaded by dust might be in a state of enhancement and that when neoplastic changes occurred the abnormas cells might quickly be recognized as 'not self' an destroyed before clinically apparent neoplasi㑊 could develop.

This work was supported by a research grant from the Welsh Hospital Board.

We are indebted to our colleagues Dr. E. A. Danino, Dr. T. W. Davies, and Mr. C. J. Evans for access to their case notes.

\section{REFERENCES}

Ashley, D. J. B. (1967). Lung cancer in miners. Thorax, 23, 87. and Davies, H. D. (1967). Cancer of the lung: histology a r biological behavior. Cancer (Philad.), 20, 165.

Bignall, J. R. (1955). Bronchial carcinoma: survey of 317 patient Lancet, 1, 786.

- and Moon, A. J. (1955). Survival after lung resection for bror chial carcinoma. Thorax, 10, 183

Doll, R., and Hill, A. B. (1952). A study of the aetiology of carcinom $\overrightarrow{\sqrt{8}}$ of the lung. Brit. med. J., 2, 1271.

Ederer, F., and Mersheimer, W. L. (1962). Sex difierences in the survival of lung cancer patients. Cancer (Philad.), 15, 425.

Hanbury, W. J. (1964). Bronchogenic carcinoma in women. Thora $\frac{\vec{x}}{0}$ 19. 338

Kreyberg. L. (1962). Histological Lung Cancer Types. Acta path. scand Suppl. 157 McKusick. V. A. (1962). On the X chromosome of man. Quart. Re
Biol., 37. 69.

Mason, G. A. (1949). Cancer of the lung: review of a thousand case Lancet, 2, 587

Myddelton, G. (1965). Carcinoma of brenchus. Ibid., 2, 796.

Nicholson, W. F., Fox, M., and Bryce, A. G. (1957). Review of 919 cases of bronchial carcinoma with results of treatment. Ibid., \& 296.

Registrar General (1965). Statistical Review of England and Wales fo요 the year 1963. Part I. Tables, Medical. H.M.S.O., London.

Shinton, N. K. (1963). Differences in biological characteristics various histological types of lower respiratory tract tumours. Bri J. Cancer, 17, 222.

Vincent, T. N.. Satterfield, J. V., and Ackerman, L. V. (1965). Carco noma of the lung in women. Cancer (Philed.), 18559.

Whitwell, F. (1961). The histopathology of lung cancer in Liverpoof the specificity of the histological cell types of lung cancer. Brit. 0 Cancer, 15, 440 